\title{
ANÁLISE ECONÔMICA DOS PRINCÍPIOS AMBIENTAIS DO POLUIDOR PAGADOR E USUÁRIO PAGADOR
}

\author{
Jéssica Gonçalves ${ }^{*}$
}

Resumo: O presente artigo analisa economicamente os princípios ambientais do Poluidor Pagador e Usuário Pagador para demonstrar que a interdisciplinaridade entre o direito e a economia assegura o desenvolvimento econômico e a preservação ambiental. Após a crise do antropocentrismo e da ecologia profunda, verifica-se que o Estado não mais ignora os desequilíbrios ecológicos, passando a proteger juridicamente o meio ambiente pelo critério do desenvolvimento sustentável, solidariedade entre as gerações presentes e futuras e dos princípios ambientais. Nesse contexto, as normatizações principiológicas do Poluidor Pagador e Usuário Pagador asseguram a compatibilização entre a preservação do meio ambiente e o desenvolvimento econômico, pois não representam apenas dimensões jurídicas, mas também conceitos econômicos neoclássicos das externalidades e da valorização monetária dos bens e recursos ambientais como forma de diminuir a degradação ambiental.

Palavras-chave: Direito Ambiental Econômico. Desenvolvimento Sustentável. Solidariedade entre Gerações. Princípio do Poluidor Pagador. Princípio do Usuário Pagador.

1 * Graduada em Direito pela Universidade do Sul de Santa Catarina - UNISUL-SC. Formada pela Escola da Magistratura do Estado de Santa Catarina (módulo I e módulo II). Pós Graduada em Direito Processual Civil pela Universidade Federal de Santa Catarina - UFSC-SC. Pós Graduada em Direito Público pela Universidade Regional de Blumenau - FURB-SC. Pós Graduada em Direito Aplicado pela Universidade Regional de Blumenau - FURB-SC. Mestranda do Curso de Direito da Universidade Federal de Santa Catarina - UFSC-SC. E-mail: jessic.goncalves@hotmail.com 


\section{INTRODUÇÃO}

O progresso apresenta-se como a grande promessa da evolução e da história humana, porém, junto com ele, a exploração da superfície dos recursos naturais assola o homem na atualidade.

Partindo dessa premissa, o cenário social sobrevive em meio ao paradoxo da necessidade de desenvolvimento econômico com a manutenção do direito ambiental, de modo que as teorias políticas clássicas como o antropocentrismo e a ecologia profunda restam superadas pelo pensamento do Direito Ambiental Econômico.

Dessa forma, a formação do pensamento ecologizado em consonância com o dever de precaução, encontra na interdisciplinaridade entre o direito e a economia conceitos que reconhecem que os recursos naturais não são inesgotáveis e que auxiliam o desenvolvimento sustentável e a solidariedade entre gerações para uma melhoria de qualidade de vida das populações.

Além disso, as intensificações dos fenômenos de degradação ambiental colocam o Estado numa incômoda posição na sociedade contemporânea de modo a redefinir seu papel como de Direito Ambiental.

Ainda que de cunho teórico abstrato, o Estado de Direito Ambiental normatiza a natureza por meio de leis, declarações e principalmente pela inclusão de princípios que assegurem o meio ambiente como um direito fundamental e indispensável para a sobrevivência do próprio homem.

Assim este novo Estado para firmar seus preceitos jurídicos socorre-se da simbiose com o pensamento econômico, adaptando conceitos desta ciência para garantir que o desenvolvimento seja compatibilizado com a preservação e/ou conservação do meio ambiente.

E, a partir desse instrumento Estatal baseado em princípios ambientais é que o presente artigo visa analisar a transver- 
salidade da economia nos preceitos, isto é, examinar economicamente se os princípios ambientais como Poluidor Pagador e Usuário Pagador asseguram o desenvolvimento econômico e a proteção ambiental.

Para além das dimensões jurídicas, os mencionados princípios serão abordados pelos critérios econômicos neoclássicos como o conceito da externalidade e da valorização monetária dos bens ambientais.

A ideia é demonstrar que embora em matéria ambiental direito e economia pareçam antagônicos, uma vez que há um discurso apelativo de que esta ciência é a responsável pela degradação e exploração daquela, eles não são repelentes, pois se unem para o desenvolvimento de métodos e técnicas de valoração monetária dos impactos e das intensas transformações que acarretam no surgimento de desequilíbrios ecológicos.

Portanto, o direito se vale de conceitos econômicos para construir os Princípios do Poluidor Pagador e Usuário Pagador com o escopo de diminuir a degradação ambiental e garantir o pleno desenvolvimento social, conforme será demonstrado neste artigo.

\section{A SUPERAÇÃO ENTRE O ANTROPOCENTRISMO E A ECOLOGIA PROFUNDA: POR UM DIREITO AMBIENTAL ECONÔMICO}

A relação entre o homem e a natureza é intrínseca a própria evolução da espécie humana de modo que a civilização primitiva embora tivesse a compreensão da humanização da Terra, não deixou de imprimir-lhe sua marca com uma degradação lenta e supostamente apta a se recuperar.

No entanto, segundo Fraçois Ost (1995) é a partir de Descartes, com a expressão "fábula de um novo mundo" que a humanidade rompe com o paradigma do Universo criado pelas mãos de Deus e o aceita como inventado pela ciência dando azo à ruptura entre o homem e a natureza. Ainda nessa perspectiva, 
Galileu com seus "óculos de observação" corrobora para a ideia de que o Universo se apresenta em movimento no qual o homem tem a capacidade de explorá-lo.

Dessa forma, a partir desse cenário de evangelização do homem como a medida e o centro do Universo, legitimado pela criação jurídica do direito absoluto de dispor da propriedade, a natureza foi subjugada à satisfação das necessidades dos "senhores da Terra"; (OST, 1995).

Dois séculos de transformação da natureza conduziram ao resultado de deteriorização do planeta, no qual se vive, hodiernamente, em um período de intensas transformações técnico - científicas, as quais engendram fenômenos de desequilíbrios ecológicos que, se não forem remediados, no limite, ameaçam a vida em sua superfície. (GUATTARI, 2001, p. 7).

Segundo José Rubens Morato Leite e Luciana Cardoso Pilati $(2011$, p. 9) nos séculos XIX e XX a ideologia liberal individualista contribuiu para a conduta de apropriação que, somado aos avanços tecnológicos e científicos da Revolução Industrial e Pós Industrial, intensificou a exploração dos recursos naturais e o deixou, inclusive, à mercê das regras do mercado.

A crise ambiental, portanto, decorre de um fenômeno segundo o qual os homens, para satisfação de suas novas e múltiplas necessidades, que são ilimitadas, disputam os bens da natureza, por definição, limitados. Além disso, a tecnologia industrial e a explosão populacional aceleram os problemas ambientais, sob um enfoque de riscos globais. (MILARÉ, 2011, p. 65).

Nesse âmbito crítico e urgente em que se encontra o meio ambiente, o lema da consciência ecológica e da proteção ambiental se arraiga entre autores que invertem a lógica do antropocentrismo para atribuir um caráter divino à mãe natureza, pois "o homem transformou a Terra, domesticou suas superficies vegetais, tornou-se senhor de seus animais. Mas não é o senhor do mundo, nem mesmo da Terra." (MORIN, 2003, p. 176). 
A consolidação do ponto de vista da natureza, segundo a Ecologia Profunda, significa, de acordo com de Fritjof Capra ${ }^{2}$ não separar o ambiente natural nem qualquer outro ser, pois o mundo é como uma teia de fenômenos essencialmente interligados e interdependentes, reconhecendo que todos estão inseridos nos processos cíclicos da natureza e deles são dependentes.

O biocentrismo/ecocentrismo é um movimento cultural que se baseia numa filosofia de aliança com a mãe terra, no qual a natureza transporia do modelo de objeto dos interesses do homem para ser dotada de dignidade e ser sujeito de direitos fundamentais. Entretanto, a tese da natureza divinizada sem que se possa nela tocar ou desenvolver economicamente os países também se apresenta centrada apenas em si, sem que seja capaz de superar os dilemas globais.

A superação da noção romântica da natureza como um santuário intocável, permite o desenvolvimento com vistas à proteção, pois conforme lembra Édis Milaré (2011, p. 72), é falso o dilema "desenvolvimento ou meio ambiente", na medida em que, sendo este fonte de recurso para aquele, ambos devem harmonizar-se e complementar-se.

Assim, tanto o antropocentrismo como a ecologia profunda, em razão do domínio unilateral de perspectivas teóricas voltadas somente para si, promovem uma crise para além da ecológica, perfectibilizada no vínculo e no limite do homem com a natureza (OST,1995).

Desse modo, somente a partir da simbiose entre ambas é que um novo paradigma se formará, criando a natureza projeto. Isso é, com o rompimento do método cartesiano de Descartes e, com apoio na epistemologia da complexidade dialética, haverá a percepção da interdependência entre o homem e a natureza (embora diferentes, cada qual contém e depende um do outro sem que se reduzam), como base para o dever ético entre as gerações pela transmissão de um patrimônio comum (OST, 1995).

2 Disponível em http://pt.wikipedia.org/wiki/Ecologia_profunda visualizado em 30 de março de 2014 
Ademais, o Estado intervencionista não pode mais ignorar os desequilíbrios ecológicos bem como a sociedade não pode deixar de pensar o meio ambiente como um ramo a ser discutido em nível de escala global, sem que se deixe de compatibilizar o tema com o desenvolvimento econômico.

A questão é atender, portanto, dentro de um processo contínuo de planejamento, as exigências de ambos, sem que a política ambiental signifique obstáculo ao desenvolvimento (MILARÉ, 2011, p. 72) ou que este fique atrofiado a noção econômica, uma vez que não cabe mais reduzir o "desenvolvimento ao crescimento" (MORIN, 2003, p. 102).

Partindo dessa premissa, o Direito Ambiental Econômico cuja normatização visa organizar a questão ambiental e o direito econômico (GUARESCHI, 2013, p. 3), ultrapassa o antropocentrismo e a ecologia profunda na medida em que não ignora que a gestão racional dos recursos naturais é a base material para o progresso humano (MILARÉ, 2011, p. 72).

A teoria econômica como ramo que descreve as escolhas humanas, e ainda, os seus comportamentos futuros, influencia o Direito Ambiental, tendo em vista que busca determinar quais escolhas garantem a preservação da natureza, bem como quais comportamentos alcançam o desenvolvimento econômico para que a finalidade almejada (bem estar coletivo) possa ser desfrutada (SOARES, 2005).

Nesse sentido, a importância da análise do direito com a economia está claramente descrita nas palavras da autora Cristiane Derani (2001, p. 111):

A economia ambiental analisa os problemas ambientais a partir do pressuposto de que o meio ambiente - precisamente parte dele que pode ser utilizada nos processos de desenvolvimento da sociedade industrial - é limitado, independentemente da eficiência tecnológica para sua apropriação. $\mathrm{O}$ esgotamento dos recursos naturais, responsável pela assim chamada crise do meio ambiente, é identificado em duas clássicas tomadas: 
com o crescente consumo dos recursos naturais (minério, água, ar, solo, matéria-prima) como bens livres (free gifts of nature) e com os efeitos negativos imprevistos das transações humanas.

Critério ambiental econômico auxilia o equilíbrio que envolve a escassez de recursos ambientais com a garantia da qualidade de vida sadia, ao mesmo tempo, em que inclui no processo produtivo a internalização das externalidades para que os agentes, potencialmente poluidores, incorporem em seus lucros os custos com a degradação ambiental ou, com o emprego de técnicas que visem evitá-los ou diminuí-los (CHEMIN, 2005).

Tal situação nada mais corporifica que o art. $225 \mathrm{c} / \mathrm{c}$ o art. 170, VI, ambos da Constituição Federal que asseguram o direito de terceira dimensão vinculado ao meio ambiente ecologicamente equilibrado e o desenvolvimento econômico e, por isso, a teoria econômica ambiental neoclássica permite compreender a complexidade dos problemas atuais e preservação do meio ambiente natural conjugada com a garantia do desenvolvimento, ou seja, a ideia de reciprocidade entre eles (GERENT, 2008, p. 274).

\section{O DESENVOLVIMENTO ECONÔMICO A PARTIR DO CRITÉRIO SUSTENTÁVEL E DA SOLIDARIEDADE ENTRE AS GERAÇÕES}

Conforme mencionado no tópico anterior, a partir do movimento que a natureza faz do homem e esse dela, mas, sobretudo pela tomada de decisão humana (ação coletiva) que opera efeitos no futuro, progressivamente o conceito antropocêntrico e ecocêntrico são substituídos pela noção do direito ambiental econômico, até porque a Constituição Federal assegura o direito ambiental e desenvolvimento econômico.

Dessa forma, já se encontra ultrapassada o senso de proibição de beneficiar-se a humanidade e os países de avançarem tecnologicamente, embora o processo de mudança deva 
preservar o ecossistema para as gerações futuras de maneira urgente e real, conforme descreve Frijot Capra (2005, p. 99):

As organizações humanas precisam passar por uma mudança fundamental, tanto para se adaptar ao novo ambiente empresarial quanto para tornar-se sustentáveis do ponto de vista ecológico. Esse duplo desafio é urgente e real, de modo que as recentes e exaustivas discussões sobre a mudança empresarial estão plenamente justificadas.

Nesse aspecto, a tentativa de compatibilizar os dois direitos fundamentais (desenvolvimento econômico e proteção ao meio ambiente) arrolados pela Constituição assume o nome de desenvolvimento sustentável que significa a conscientização da necessidade de desenvolver economicamente, porém garantindo a preservação para as futuras gerações.

Adotado pela conferência na declaração do $\mathrm{Rio}^{3}$ e na Agenda 21 como meta a ser alcançada por todos os países o desenvolvimento sustentável foi definido pela Comissão Mundial sobre o Meio Ambiente e Desenvolvimento (1991, p. 46) como aquele que atende às "necessidades do presente sem comprometer a possibilidade de as gerações futuras atenderem as suas próprias necessidades", podendo também ser empregado com o significado de "melhorar a qualidade de vida dentro dos limites da capacidade do suporte dos ecossistemas" (Governo do Estado de São Paulo/SP, 1991, p. 10).

Dessa forma, o conceito de desenvolvimento sustentável está intimamente relacionado com a solidariedade intergeracional, pois há que se desenvolver de maneira sustentável (economicamente avançando e preservando), desde que inclua nesse contexto a garantia para as gerações sincrônicas e diacrônicas como um dever ético.

Consoante esclarece Fraçois Ost (1995) deve a sociedade assumir um projeto solidário e universal, fundamentado no

3 Princípio 4: "Para alcançar o desenvolvimento sustentável, a proteção ambiental constituirá parte integrante do processo de desenvolvimento e não pode ser considerada isolada deste." 
conceito de humanidade de Kant, que implique em conservar a natureza como um dever assimétrico do homem e não como um direito desta, justificado pela dignidade em qualquer lugar e tempo dos beneficiários.

Especificadamente, que cada geração utilize economicamente os recursos que dispõe, de forma a transmitir às demais (estas longínquas pela descendência abstrata) um nível de qualidade ambiental semelhante ao que ela própria recebeu.

Para essa construção de sociedade sustentável para nossos filhos e as gerações futuras tem que repensar, segundo Frijot Capra (2005, p. 99) "uma boa parte das nossas tecnologias e instituições sociais, de modo a conseguir transpor o enorme abismo que se abriu entre os projetos humanos e os sistemas ecologicamente sustentáveis da natureza".

O desenvolvimento sustentável implica nos dizeres de Cristiani Derani (2001, p. 132):

Um desenvolvimento harmônico da economia e ecologia que devem ser ajustados numa correlação de valores onde o máximo econômico reflita igualmente um máximo ecológico. Na tentativa de conciliar a limitação dos recursos naturais com o ilimitado crescimento econômico, são condicionadas à consecução do desenvolvimento sustentável mudanças no estado da técnica e na organização social.

Logo, o desenvolvimento sustentável e a solidariedade entre as gerações refletem a ideia de eficiência econômica, social e ambiental, "que significa melhoria da qualidade de vida das populações atuais sem comprometer as possibilidades das próximas gerações, com o reconhecimento de que os recursos naturais não são inesgotáveis" (MONTIBELLER FILHO, 2004, p. 19), e a impossibilidade de um completo desenvolvimento "se os caminhos trilhados para sua consecução desprezarem um sistema de exploração racional e equilibrada do meio ambiente" (COSTA NETO, 2003, p. 59).

Portanto, é possível afirmar que o desenvolvimento econômico deve obedecer ao critério sustentável cuja primeira ideia 
é a conjugação do respeito ao ambiente ecologicamente equilibrado (art. 225 da CF) e o direito ao progresso econômico (art. 170 da CF). Já o segundo o aspecto se perfaz na noção intertemporal no qual as atividades econômicas do presente não podem explorar os recursos naturais de tal monta que sacrifique os direitos e interesses das futuras gerações em utilizá-los e gozar da qualidade de vida.

\section{A CRISE AMBIENTAL E A NECESSIDADE DE PROTEGER JURIDICAMENTE O MEIO AMBIENTE: A CONSOLIDAÇÃO DO NOVO PAPEL DO ESTADO}

A partir da década de 1970, conforme lecionam José Rubens Morato Leite e Luciana Cardoso Pilati (2011, p. 9), há uma conscientização do esgotamento dos recursos naturais, do risco de catástrofes ambientais e da incompatibilidade entre o modelo capitalista e a manutenção da qualidade de vida, isto é; destaca-se uma sociedade de risco $^{4}$, marcada pelo perigo iminente em face do contínuo crescimento econômico.

Dessa realidade de complexidade de riscos, problemas globais de poluição, aquecimento global, mudanças climáticas, contaminações destrutivas da biodiversidade, surge uma política de conscientização sobre a crise ambiental e a necessidade de proteger juridicamente o meio ambiente.

Por essa razão, na perspectiva atual a solução para efetividade da tutela dos direitos fundamentais quais sejam: meio ambiente ecologicamente equilibrado e o desenvolvimento econômico não mais reside na solitária ideia da privatização com seus três pilares: propriedade privada, mercado que assegure a circulação e o critério da responsabilidade.

Para além da mencionada lógica de privatizar o ambiente

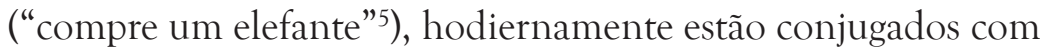

4 Expressão extraída do Livro Ulrich Beck. La sociedad del riesgo: hacia uma nueva modernidade. Barcelona: Piados, 2001.

5 Expressão extraída do Livro $A$ natureza à margem da lei: a ecologia à prova do direito. Fraçois Ost. Instituto Piaget, 1995. p. 155 
alternativas como a normatização da conduta cautelosa e marco transversal da solidariedade como forma de preservação para o futuro, até porque se as "gerações atuais continuarem a utilizar o meio ambiente sem adoção de medidas restritivas, acabarão por comprometer, de forma irreversível, os interesses das vindouras" (CANOTILHO, José Joaquim Gomes, 1995, p. 98).

Assim, a proliferação dos problemas ecológicos traduz um novo paradigma sob a dimensão voltada para a premissa de que o desenvolvimento econômico deve se ajustar ao meio ambiente ecologicamente equilibrado já que esse se perfaz na luz de todos os demais direitos fundamentais.

Especificadamente, a crise do meio ambiente global demanda um novo papel do Estado e coloca em pauta o status da ecologia como bem a ser protegido juridicamente, conforme explica Amandino Teixeira Nunes Júnior (2004, p. 299):

Isso implica o surgimento de um novo estado e de uma nova cidadania, que têm plena consciência da devastação ambiental, planetária e indiscriminada, provocada pelo desenvolvimento, aspirando assim novos valores como a ética pela vida, o uso racional e solidário dos recursos naturais, o equilíbrio ecológico e a preservação do patrimônio genético.

Assim, a problemática ambiental deve receber tratamento diferenciado por todas as áreas do conhecimento, inclusive no âmbito dos estudos a respeito do Estado, haja vista que é condição de sobrevivência das presentes e futuras gerações.

Nesse âmbito, o agravamento dos problemas ambientais e a noção crescente da existência de riscos potenciais criam um cenário de proteção jurídica ao meio ambiente, isto é; impõe ao Estado de Direito o desafio de inserir entre suas tarefas prioritárias a proteção do meio ambiente, consolidando o novo papel do Estado como gestor adequado dos riscos.

Partindo desse pressuposto, a necessidade de redimensionar esse papel do Estado transparece a ideia de um novo regime jurídico que, segundo François Ost (1995, p. 352) é 
possível com a "Transmissão de um Patrimônio Comum", ou seja, um novo estatuto que transcenda a noção da natureza como objeto (antropocentrismo) ou como sujeito (ecologia profunda), mas que reconhece a interação recíproca entre o homem e a natureza de forma complexa, transtemporal, translocal e híbrida.

Ocorre que esse prolongamento de uma série de diferentes categorias jurídicas e mudanças paradigmáticas capaz de impor regras coercitivas de limitação, controle e gestão para assegurar um ambiente ecologicamente equilibrado no Brasil foi possível com a consolidação do "Estado de Direito Ambiental" (José Rubens Morato Leite) ou o "Estado Constitucional Ecológico" (José Joaquim Gomes Canotilho).

A expressão, segundo José Rubens Morato Leite e Luciana Cardoso Pilati (2011, p. 10-11) significa um conceito de cunho teórico abstrato que abarca elementos jurídicos, sociais e políticos na busca de uma condição ambiental capaz de favorecer a harmonia entre os ecossistemas e, consequentemente, garantir a plena satisfação da dignidade para além do ser humano, numa situação ambiental ecologicamente sustentável.

Nessa seara, a construção desse Estado passa, necessariamente, pelas disposições constitucionais, pois são elas que exprimem os valores e os postulados básicos da comunidade nas sociedades e, no Brasil, além da Constituição da República Federativa de 1988, a Lei de Política Nacional do Meio Ambiente (Lei n. 6938/81), Lei de Ação Civil Pública (Lei n. 7347/85), são os instrumentos responsáveis pela implementação do Estado de Direito Ambiental na medida em que concretizam políticas de proteção ao meio ambiente.

Portanto, a crise ambiental impôs a necessidade de proteger juridicamente o meio ambiente, o que se tornou possível com a consolidação de um novo papel do Estado pautado na construção abstrata do Estado de Direito Ambiental que projeta normas, leis e princípios em prol do meio ambiente. 
O aparato do Estado de Direito Ambiental é em última escala o que permite conciliar, no mundo real, o direito fundamental ao meio ambiente e o desenvolvimento na medida em que institucionaliza a responsabilidade ecológica e os princípios econômicos ambientais.

\section{PRINCÍPIOS ESTRUTURANTES DO ESTADO DE DIREITO AMBIENTAL}

$\mathrm{Na}$ perspectiva atual de desenvolvimento econômico pautado na cautela e na preservação do meio ambiente, surge, conforme mencionado no tópico anterior, o regime jurídico do Estado de Direito Ambiental como mecanismo de garantir a gestão dos recursos naturais vinculado à criação de princípios.

A partir da leitura da Constituição da República Federativa do Brasil de 1988 a doutrina aponta como princípios estruturantes do Estado de Direito Ambiental o da precaução, prevenção, responsabilização, poluidor pagador, participação, cidadania, democracia, informação, proibição do retrocesso ecológico e mínimo existencial ecológico (MORATO LEITE e AYALA, 2012, p. 229).

Em que pese referidos princípios sejam capazes de recepcionar o modelo de Estado de Direito Ambiental que expressa matrizes ambientais que necessitam de proteção, não serão todos objetos de análise uma vez que o escopo da presente investigação são os princípios ambientais econômicos.

Nessa senda, em razão do presente artigo ter por objetivo analisar economicamente os princípios ambientais ou, por outras palavras, encontrar na teoria econômica a legitimidade para criação dos princípios ambientais, limitar-se-á o estudo aos princípios do poluidor pagador e usuário pagador.

Isso porque uma das formas de equilibrar os interesses econômicos e o ambiente ecologicamente equilibrado se dá não apenas com a Lei, mas também com princípios econômicos na medida em que os conceitos de internalizar as externalidades/ 
incorporar nos lucros os custos com uma futura degradação ambiental e a quantificação dos recursos naturais para evitar um custo zero, antes de natureza meramente econômica passam a integrar a proteção ambiental por intermédio dos princípios, respectivamente, do poluidor pagador e usuário pagador.

A ideia trazida da economia para o direito ambiental é, perceber, portanto, que a atividade do homem ao retirar do meio ambiente matéria prima para transformar em produtos para o consumo e a devolver para o mesmo ambiente de forma modificada ou alterada precisa ser incorporado por aquele que pratica a atividade econômica (arcar com as externalidades da sua atividade) pelo viés do princípio do poluidor pagador (GERENT, 2008, p. 275).

Além disso, as medidas de proteção dos bens naturais por meio do princípio do usuário pagador (imposição do preço para evitar a escassez) devem ser cumpridas com vistas a evitar o custo zero e a consequente exploração (GERENT, 2008, p. 275).

Neste sentido, segundo a ótica neoclássica, há um grande número de princípios econômicos que são aplicados para obter um ambiente sustentável. Para esta corrente, o ponto de partida é a questão levantada por Arthur Cecil Pigou, da falha dos mecanismos de mercado implicando no surgimento de externalidades (COSTA, FREITAS E OLIVEIRA, 2008, p. 4). E, continuam os Autores:

Desse modo, a proposta de Pigou para resolver esses impasses ocasionados pelos efeitos negativos na utilização de recursos naturais por mais de um agente, é a intervenção do Estado. Essa concepção, parte do pressuposto de que é possível a correção das externalidades negativas mediante a cobrança, por parte do Estado, do custo social da degradação ambiental. Este princípio, denominado como Princípio do Poluidor- Pagador, confere direitos que permitem a internalização de custos que seriam normalmente assumidos pelo poluidor ou usuário (externalidades). 
Nessa senda, o Estado intervencionista não pode mais ignorar os desequilíbrios ecológicos e, dado o caráter de urgência o Direito é instado a se posicionar, com textos, sanções, leis, declarações e princípios (OST, 1995, p. 155).

Portanto, a partir da natureza regulamentada (OST, 1995, p. 155), o Estado de Direito Ambiental perfectibilizado sob o manto dos princípios do poluidor pagador e do usuário pagador dá azo à valorização econômica do meio ambiente com vistas a assegurar o paradoxo atual: preservar a natureza, mas também garantir o desenvolvimento econômico.

\subsection{A responsabilidade pelas externalidades por meio do princípio do poluidor pagador}

O desenvolvimento econômico e a preservação ambiental passam a conviver juridicamente e socialmente quando os riscos de danos ambientais são reduzidos a partir da normatização pelo Estado de princípios. E, nesse âmbito, o princípio do poluidor pagador de caráter preventivo/econômico e cautelar/ reparador visa incluir no processo produtivo os custos com as externalidades.

Primeiramente cumpre explicar que em termos técnicos, segundo Weydmann (2005, p. 290), a existência de externalidades indica que o agente econômico ao produzir considera apenas o custo marginal privado ( $\mathrm{Cmg}$ ) e não o custo incremental de poluir, denominado custo marginal externo (Cme). A combinação do Cmg com o Cme resulta no custo marginal social (Cms), que seria situação ideal onde as externalidades estariam internalizadas na contabilidade social.

Desse modo, o conceito de externalidades desenvolvido com a economia ambiental neoclássica significa que os custos decorrentes do processo produtivo podem ser positivos quando, por exemplo, uma inovação tecnológica gera uma série inédita de aplicações com crescimento do emprego e do investimento e, por outro lado, podem ser negativos quando os custos da 
degradação ambiental do ar não estão contemplados no valor de compra de um automóvel (Sarcinelli, 2008, p. 11).

$\mathrm{Ou}$, ainda, segundo Chemin $(2005$, p. 124) as externalidades podem ser entendidas "sempre que terceiros ganhem sem pagar por seus beneficios marginais ou percam sem ser compensados por suportarem malefício adicional", isto é; há desequilíbrio entre os custos das empresas (custos privados) e os custos assumidos pela sociedade (custos sociais).

E, em nível ambiental o que se observa é uma ineficiência de Pareto pois os cálculos privados de custos ou benefícios diferem dos custos ou benefícios da sociedade, já que as externalidades mostram-se negativas, como bem recorda Oscar Sarcinelli (2008, p. 11):

A ineficiência de Pareto, nas situações onde as externalidades existem, resulta de que $\mathrm{Cmg}<\mathrm{Cms}$ e, portanto, a externalidade negativa implica em maiores taxas de poluição uma vez que os custos estariam subestimados pelos agentes. Uma consequência direta destas situações esta no fato de que ela possibilita a permanência no setor de agentes economicamente ineficientes e que não existiriam caso houvesse a internalização do Cme, ou custo de poluir.

E, nas palavras de Varian (1994, p.750) as situações de externalidades negativas apresentam consequências especialmente nos casos de poluição:

No caso da poluição, o preço dos produtos privados que a causam é inferior ao custo social pago por quem sofre seus efeitos. As externalidades tem relação com os direitos de propriedade, cuja indefinição dificulta que as pessoas negociem seus direitos a semelhança de uma transação comum.

Nessa seara, o pano de fundo do conceito de externalidade é o paradoxo entre os custos privados e os custos sociais, de modo que a não contabilidade desses custos nos preços dos produtos 
acarreta prejuízos à sociedade que "sofre com a transformação da matéria prima em produtos comercializáveis e, por outro lado, tem-se o lucro privativo do fabricante do bem econômico" (RODRIGUES, 2002, p. 345).

Partindo dessa teoria das externalidades (Marshall), se cria uma concepção de fim do "ciclo econômico clássico, que abrange só a produção, distribuição e consumo, sem se preocupar com o destino dos resíduos em cada fase do ciclo." (ARAGÃO, 1997, p. 27) e, se imputa a responsabilidade pelo processo produtivo ao empreendedor que passa arcar com os custos resultantes de sua poluição por meio do Princípio do Poluidor Pagador.

Nesse aspecto, como forma de internalizar as externalidades negativas e com vistas a diminuir o cenário de dano ambiental, surge o princípio normativo de caráter econômico denominado Princípio do Poluidor Pagador.

Assim, a externalidade negativa (exemplo: poluição) causada pela atividade empresarial deve ser suportada pelo empreendedor dentro do seu processo produtivo porque não é lícito socializar os prejuízos. Ou, por outras palavras, segundo Lemos (2008, p. 157) a necessidade de internalização total dos custos da poluição, por intermédio do Princípio do Poluidor Pagador permite que externalidades ambientais, ou seja, os custos das medidas de proteção ao meio ambiente repercutam nos custos finais de produtos e serviços cuja produção esteja na origem da atividade poluidora.

O Princípio do Poluidor Pagador consagra, portanto, a ideia "de que aquele que se utilizar dos recursos naturais deverá pagar integralmente pelos impactos que provocar, ou seja, a obrigação da reparação de todos os danos causados ao meio ambiente" (SOUZA, 2003, p. 247).

Embora tenha essa denominação que induz a expressão "pagar para poluir" o sofisma não procede (não se "compra” o direito de poluir), ao contrário, indica que o Empresário deve de maneira preventiva adotar os instrumentos para reduzir os impactos da sua atividade econômica, já que o "pagamento 
pecuniário e a indenização não legitimam a atividade lesiva ao ambiente, pois, o enfoque há de ser sempre a prevenção; entretanto, uma vez constatado o dano ao ambiente, o poluidor deverá repará-lo" (BELTRÃO, 2013, p. 230).

Dessa forma, o princípio está normatizado em diversos diplomas a iniciar pela Declaração do Rio de Janeiro adotou, em seu Princípio $n^{\circ} 16$, o Princípio do Poluidor-Pagador, que afirma:

As autoridades nacionais devem procurar assegurar a internalização dos custos ambientais e o uso de instrumentos econômicos, levando em conta o critério de quem contamina, deve, em princípio, arcar com os custos da contaminação, levando-se em conta o interesse público e sem distorcer o comércio e os investimentos internacionais.

Corrobora com a mencionada declaração a Lei 6.938/81, de 31 de agosto de 1981 (Política Nacional do Meio Ambiente) que estabelece "a imposição ao usuário, da contribuição pela utilização dos recursos ambientais com fins econômicos e da imposição ao poluidor e ao predador da obrigação de recuperar e/ou indenizar os danos causados."

Além disso, foi recepcionado pela Constituição da República Federativa do Brasil em seu art. 225, parágrafo 3, que prescreve: "as atividades e condutas lesivas ao meio ambiente sujeitarão os infratores, pessoas físicas ou jurídicas, às sanções penais e administrativas, independentemente da obrigação de reparar os danos causados."

Entretanto, para além da dimensão jurídica qual seja; identificação do poluidor para que seja responsabilizado, também se vislumbra uma análise econômica do mencionado princípio na medida em que estimula a utilização racional dos recursos ambientais escassos de modo que o empreendedor suporte o cálculo dos custos de reparação do dano ambiental e empregue as medidas necessárias para assegurar que o meio ambiente não seja degradado. 
Assim, considerando que os recursos naturais têm valoração econômica, a internalização dos custos decorrentes de seus usos pelo processo produtivo induz, segundo Juliana Gerent (2008, p. 284), a elevação dos "custos das empresas que deles se utilizam para gerar a possibilidade de não mais os empregar no processo produtivo, buscando outras alternativas menos impactantes ao meio ambiente"

Portanto, o Princípio do Poluidor Pagador está vinculado à economia porque introduz o conceito de externalidades no campo ambiental de modo que as atividades empresariais que utilizam recursos naturais passam a suportar os custos, no processo produtivo, da alocação da matéria prima.

\subsection{A valorização monetária dos bens naturais pelo princípio do usuário pagador}

A teoria econômica neoclássica apresenta dois binômios: o primeiro, como visto no tópico anterior que imputa a responsabilidade pela internalização das externalidades ao agente empreendedor por meio do Princípio do Poluidor Pagador. Já o segundo, significa a valoração monetária dos bens naturais pelo mercado por intermédio do Princípio do Usuário Pagador, objeto deste item.

A diferença entre ambos reside no aspecto que o Princípio do Poluidor Pagador tem caráter reparatório e punitivo, enquanto o Princípio Usuário Pagador enseja uma contrapartida remuneratória pela outorga do direito de usar e gozar daquele recurso natural, razão pela qual a aplicação de ambos ao empreendedor não gera bis in idem (CHIUVITE, 2010, p. 37).

Atualmente, o cenário de raridade do recurso explorado, poluições emitidas e necessidades de prevenir catástrofes, impõe, nos dizeres de Paulo Affonso Leme Machado (2006, p.59), à cobrança dos usuários de determinada quantia de exploração.

A exploração do homem tornou escassos os bens necessários para sua sobrevivência e, por conseqüência, despertou a 
sociedade para uma consciência ambiental atrelada ao desenvolvimento econômico.

Assim, na busca de alternativas que preservam o meio ambiente e, rejeitando o "crescimento zero", urge a necessidade de uma regulamentação desse impasse por meio de uma política de custos direcionados aqueles que utilizarem os bens naturais não como uma sanção, mas como garantia de preservação do bem jurídico

O caráter quantificador dos recursos naturais com o escopo de evitar o custo zero e, com este a exploração, parte do pressuposto que os recursos ambientais são escassos e, portanto, sua produção e consumo geram escassez.

Assim, tendo em vista que o meio ambiente é um direito de todos, a utilização gratuita do recurso ambiental gera um enriquecimento ilícito, de modo que a colocação de preço evita o custo zero. (CHIUVITE, 2010, p. 37). Dessa feita, passa-se a aceitar a quantificação econômica dos recursos ambientais como forma de regular e evitar abusos, impondo limites aos usuários dos bens naturais.

Previsto no art. 4º, VII, da Lei 6.938/81, de 31 de agosto de 1981 (Política Nacional do Meio Ambiente) que estabelece "a imposição ao usuário, da contribuição pela utilização dos recursos ambientais com fins econômicos" o Princípio do Usuário Pagador significa que aquele que usar os recursos ambientais deve pagar por esse uso, na medida em que está usando algo que é um bem de uso comum.

O princípio é um instrumento encontrado pelo Estado para garantir a efetivação de todos os direitos humanos, principalmente o ambiental, como disserta Bonifácio Rios Ávalos (2001, p. 26):

(...) este principio se inscribe entre los esenciales del quehacer ambiental. Se puede señalar que la identificación de este postulado constituye um paso esencial para la elaboración del Derecho Ambiental. Se puede decir que este principio 
tiene un carácter eminentemente regulador de los recursos naturales en relación con la economía de un país, pues la explotación irracional, si bien podría generar riquezas a favor de los explotadores, constituye sin embargo, una ruptura del equilíbrio ambiental.

A fruição coletiva autoriza a possibilidade de uso privado de um recurso (pagamento pelo uso do recurso), ou seja, implica na cobrança de um preço fixado pela participação do próprio Usuário Pagador, como mecanismo estatal para assegurar o equilíbrio ecológico.

Entretanto, em que pese o princípio apresente um conotativo econômico é também esta dimensão que traz questões que devem ser pensados juridicamente para uma fiel normatização. Alerta Maria Luisa Faro Magalhães (2002, p. 74) que os aspectos levantados pela economia dizem respeito à quantificação:

$\mathrm{Na}$ teoria econômica, a valoração de um bem pode ser analisada sob dois aspectos. $\mathrm{O}$ primeiro deles seria a disposição para pagamento, o quanto as pessoas pagariam por um determinado bem ou serviço.

Outro aspecto diz relação com o quanto às pessoas aceitariam como compensação monetária pelo fato de não terem acesso a determinados bens ou serviços.

Neste sentido, fácil perceber que a avaliação dos bens ambientais é subjetiva e "a valoração monetária não estabelece 'preços' para os 'recursos ambientais', para a 'vida' ou para a 'natureza'. Ela somente fixa paradigmas que representam o quanto aquele recurso ambiental significa para o grupo social”.

A resposta a essa indagação foi descrita por Antônio F. G. Beltrão (2013, p. 50) ao dissertar que o princípio não visa alijar do consumidor de um bem ambiental aqueles economicamente menos favorecidos; deve focar, portanto, na cobrança 
daqueles que usufruem em larga escala, em atividades geradoras de riquezas, visto que está sendo utilizado um patrimônio da coletividade em proveito particular.

O Princípio do Usuário Pagador, portanto, traduz a análise/avaliação econômica a partir da inclusão, ao meio ambiente, do conceito de valor econômico com o escopo de evitar ao custo zero e a exploração desmedida, contribuindo para "para a melhoria do bem-estar, do padrão de vida e para o desenvolvimento econômico e social" (COMUNE, Antonio Evaldo; MARQUES, João Fernando, 1996, p. 23).

\section{CONCLUSÃO}

A sociedade atual sobrevive em meio ao paradoxo do desenvolvimento contínuo de meios técnico-científicos e de situações potencialmente capazes de promover desastres ecológicos globais.

A partir desse contexto de crise ambiental, diversas doutrinas, centradas apenas em si, surgiram com o escopo tão somente de preservar o homem ou o meio ambiente. Dentre elas, o antropocentrismo que coloca o homem no centro das relações subjugando o meio ambiente como objeto das satisfações das suas necessidades. E, de outro, pela Ecologia Profunda busca-se o retorno do ponto de vista mãe terra com a personificação e atribuição de direito subjetivos à natureza.

Entretanto, o dualismo entre as teses não elimina a hodierna crise ambiental de modo que o direito é instado a se manifestar, criando condições normativas para um meio justo, não apenas como um simples direito ao meio ambiente (inscrito na perspectiva da natureza como objeto/antropocentrismo), tampouco na ultrapassagem para a deep ecology com a natureza sujeito.

Partindo da necessidade de eliminar o risco de degradação ambiental, o Direito une-se pelo manto da interdisciplinaridade com a economia, isto é; traz conceitos econômicos para o meio 
ambiente com o objetivo de assegurar o desenvolvimento econômico e a compatibilização com a preservação dos recursos naturais, por aquilo que se cunhou denominar de Direito Ambiental Econômico.

O Direito Ambiental Econômico traz a roupagem de tentar compatibilizar os dois direitos fundamentais (desenvolvimento econômico e proteção ao meio ambiente) por meio da normatização constitucional do desenvolvimento sustentável e da solidariedade entre as presentes e futuras gerações.

Além disso, passou-se a repensar o papel do Estado como agente capaz de eliminar a sociedade de risco atual e a realocar o direito ambiental, inserindo-o como direito fundamental constitucional, mediante a criação abstrata do Estado de Direito Ambiental, que embora apresente cunho teórico possui diversos princípios capazes de readequar a preservação ambiental e o desenvolvimento econômico.

Dentre os princípios ambientais, dois apresentam avaliação econômica com o desenvolvimento de métodos e técnicas de valoração monetária dos impactos e das intensas transformações que acarretam no surgimento de desequilíbrios ecológicos.

O primeiro, o Princípio do Poluidor Pagador transparece a matéria da economia quando abarca o conceito de externalidade negativa (exemplo: poluição) para fins ambientais. A ideia, portanto, é imputar a responsabilidade ao empreendedor pela atividade econômica lesiva ao meio ambiental, bem como que o empresário deve suportar dentro do seu processo produtivo os custos com a conduta degradadora já que não é lícito socializar os prejuízos.

O segundo, o Princípio do Usuário Pagador também conota a análise econômica na medida em que valoriza os recursos naturais, isto é disciplina que aquele que usa o recurso ambiental deve pagar por esse gozo, pois o bem em questão é de uso comum.

Portanto, a análise econômica dos princípios ambientais do Poluidor Pagador e Usuário Pagador demonstram que 
aliados as ciências econômicas os preceitos auxiliam na problemática ambiental atual e conduzem ao desenvolvimento econômico sustentável para futuras gerações.

\begin{abstract}
This article analyzes economically the environmental principles of the "Payer Polluter" and the "Payer User" to demonstrate that the interdisciplinarity between the law and the economy ensures the economic development and the environmental preservation. After the anthropocentrism and deep ecology crisis, it is verified that the State no more ignores the ecological imbalances, starting to juridically protect the environment by the sustainable development, solidarity between the present and the future generations and the environmental principles. In that context, the normatizations related to principles of the "Payer Polluter" and the "Payer User" ensure the compatibility between the environmental preservation and the economic development, because they do not represent only the juridical dimensions, but also neoclassical economic concepts of the externalities and the monetary valorization of the properties and environmental resources as a way to decrease the environmental degradation.
\end{abstract}

Keywords: Economic Environmental Law. Sustainable Development. Solidarity between the Generations. Principle of the "Payer Polluter". Principle of the "Payer User".

\title{
REFERÊNCIAS
}

ANTUNES, Paulo Bessa. Direito ambiental. Rio de Janeiro: Lúmen Júris, 2001. p. 31.

ARAGÃO, Maria Alexandra de Souza. O princípio do poluidorpagador. Pedra angular da política comunitária do ambiente. São Paulo: Coimbra, 1997. p.27.

BECK, Ulrich. La sociedad del riesgo: hacia uma nueva modernidade. Barcelona: Piados, 2001. 
BELTRÃO, Antônio F. G.. Direito Ambiental. 4 ed. rev. atual. ampl. Série Concursos Públicos, 2013.

CANOTILHO, José Joaquim Gomes. Direito do meio ambiente e crítica da razão cínica das normas jurídicas. In: Revista de Direito do Ambiente e Ordenamento do Território. Lisboa: APD, n. 1, set., 1995. p. 97-99.

CHEMIN, Juliana. A visão econômica do direito ambiental. In: Revista de Direitos Difusos. Teses de Foz de Iguaçu II, ano 6, v. 30, mar./abr., 2005. p. 122.

CHIUVITE, Telma Bartholomeu Silva. Direito Ambiental. São Paulo: Barros, Fischer e Associados, 2010.

COMUNE, Antonio Evaldo; MARQUES, João Fernando. A teoria neoclássica e a valoração ambiental. In: ROMEIRO, Ademar Ribeiro; REYDON, Bastiaan Philip; LEONARDI, Maria Lucia Azevedo (Coords.). Economia do Meio Ambiente: teoria, políticas e a gestão de espaços regionais. Campinas: Unicamp IE, 1996. p. 23.

COSTA NETO, Nicolau Dino de Castro e. Proteção Jurídica do Meio Ambiente: I Florestas. Belo Horizonte: Del Rey, 2003. p. 59.

COSTA, Geovana Specht Vital da; FREITAS, Guilherme da Silva; OLIVEIRA, Prof. Dr. Cassius Rocha de. Direito e Economia: interfaces no Princípio do Poluidor-Pagador/Usuário. IX Salão de Iniciação Científica. Porto Alegre: PUCRS, 2008. p. 1-5.

Cuidando da Terra - Uma estratégia para o futuro da vida. São Paulo: UICN - União Internacional para conservação da natureza. São Paulo: UICN - União Internacional para a Conservação da Natureza, PNUMA - Programa das Nações Unidas para o Meio Ambiente e WWF - Fundo Mundial para Natureza (Governo de São Paulo/SP, ECO 92), 1991, p. 10.

DERANI, Cristiane. Direito ambiental econômico. 2. ed. São Paulo: Max Limonad, 2001. p. 111.

GERENT, Juliana. Direito ambiental e a teoria econômica neoclássica valoração do bem ambiental. Revista Jurídica Cesumar, v. 8, n. 2, jul./dez. 2008. p. 273-289.

GUATTARI, Félix. As três ecologias. Tradução Maria Cristina F. Bittencourt. Campinas: Papirus, 2001. 
GUARESCHI, Charlene Quevedo. Análise econômica do direito ambiental e o princípio do desenvolvimento sustentável. In: Fórum Internacional Ecoinovar, 2, 2013, Santa Maria/RS. Anais... Santa Maria: Editora, set., 2013. P. 1-12.

LEMOS, Patrícia Faga Iglecias. Direito ambiental: responsabilidade civil e proteção ao meio ambiente. 2. ed. São Paulo: Ed. Revista dos Tribunais, 2008.

MACHADO, Paulo Affonso L.. Direito Ambiental Brasileiro. São Paulo: Malheiros, 2006. P. 59.

MAGALHÃES, Maria Luisa Faro. Responsabilidade civil por danos patrimoniais a recursos naturais difusos: o óbice da quantificação. São Paulo, 2002. 184f. Tese (Doutorado em Direito) - Pontifícia Universidade Católica de São Paulo, 2002. p. 74.

MILARÉ, Edis. Direito do ambiente: a gestão ambiental em foco: doutrina, jurisprudência, glossário. 7 ed. ver. atual. e reform. São Paulo: Revista dos Tribunais, 2011.

MONTIBELLER FILHO, Gilberto. O Mito do Desenvolvimento

Sustentável: meio ambiente e custos sociais no moderno sistema produtor de mercadorias. 2. ed. Florianópolis: UFSC, 2004. p. 19.

MORIN, Edgar. Terra Pátria. Traduzido do Francês por Paulo Azevedo Neves da Silva. Porto Alegre: Sulina, 2003.

NOSSO FUTURO COMUM - Comissão Mundial sobre Meio Ambiente e Desenvolvimento. 2. Ed. Rio de Janeiro: Fundação Getúlio Vargas, 1991, p. 46.

NUNES JUNIOR, Amandino Teixeira. O estado ambiental de direito. Revista de Informação Legislativa. Distrito Federal: Senado Federal, 2004, a. 41, n. 163, jul/set., 2004. p. 295-307.

OST, Fraçois. A natureza à margem da lei: a ecologia à prova do direito. Instituto Piaget, 1995. p. 155.

PILATI, Luciana Cardoso; LEITE, José Rubens Morato (Coord.). Direito Ambiental Simplificado. São Paulo: Saraiva, 2011.

RODRIGUES, Silvio. Direito Civil: responsabilidade civil. 19. ed. São Paulo: Saraiva, 2002. v. 4. 
SOARES, Remi Aparecida de Araújo, Proteção Ambiental e

Desenvolvimento Econômico - Conciliação. Ed. Curitiba, 2005.

SOUZA, Paulo Roberto Pereira de. A tutela jurisdicional do meio ambiente e seu grau de eficácia. In: LEITE, José Rubens Morato; DANTAS, Marcelo Buzaglo (Orgs.). Aspectos Processuais do Direito Ambiental. Rio de Janeiro: Forense Universitária, 2003. p. 247.

VARIAN, H. R. Microeconomia: princípios básicos. 6. ed. Tradução Maria Jose Cyhlar Monteiro. Rio de Janeiro: Elsevier, 2003.

WEYDMANN, C. L. Externalidades e mudanças da regulamentação ambiental para a suinocultura norte-americana: é possível no caso brasileiro? vol. 43. n. 2. In: Revista de Economia e Sociologia Rural. Rio de janeiro: p. 287-305. Abril - Junho de 2005.

WOLKMER, Antonio Carlos e LEITE, José Rubens Morato Leite. Estado de Direito Ambiental e Sensibilidade Ecológica: Os novos Desafios à Proteção da Natureza em um Direito Ambiental de Segunda Geração. In: (Orgs.). Os novos direitos no Brasil: natureza e perspectivas: uma visão básica das novas conflituosidades jurídicas. 2. ed. São Paulo: Saraiva, 2012. p. 219-256. 
